\title{
Impacts of storm chronology on the morphological changes of the Formby beach and dune system, UK
}

\author{
P. Dissanayake ${ }^{1}$, J. Brown ${ }^{2}$, and H. Karunarathna ${ }^{3}$ \\ ${ }^{1}$ Energy and Environment Research Group, College of Engineering, Swansea University, Singleton Park, \\ Swansea, SA2 8PP, UK \\ ${ }^{2}$ National Oceanographic Centre, Joseph Proudman Building, 6 Brownlow Street, Liverpool, L3 5DA, UK \\ ${ }^{3}$ Energy and Environment Research Group, College of Engineering, Swansea University, Singleton Park, \\ Swansea, SA2 8PP, UK \\ Correspondence to: P. Dissanayake (p.k.dissanayake@ @swansea.ac.uk)
}

Received: 16 February 2015 - Published in Nat. Hazards Earth Syst. Sci. Discuss.: 15 April 2015

Accepted: 11 June 2015 - Published: 09 July 2015

\begin{abstract}
Impacts of storm chronology within a storm cluster on beach/dune erosion are investigated by applying the state-of-the-art numerical model XBeach to the Sefton coast, northwest England. Six temporal storm clusters of different storm chronologies were formulated using three storms observed during the 2013/2014 winter. The storm power values of these three events nearly halve from the first to second event and from the second to third event. Cross-shore profile evolution was simulated in response to the tide, surge and wave forcing during these storms. The model was first calibrated against the available post-storm survey profiles. $\mathrm{Cu}$ mulative impacts of beach/dune erosion during each storm cluster were simulated by using the post-storm profile of an event as the pre-storm profile for each subsequent event. For the largest event the water levels caused noticeable retreat of the dune toe due to the high water elevation. For the other events the greatest evolution occurs over the bar formations (erosion) and within the corresponding troughs (deposition) of the upper-beach profile. The sequence of events impacting the size of this ridge-runnel feature is important as it consequently changes the resilience of the system to the most extreme event that causes dune retreat. The highest erosion during each single storm event was always observed when that storm initialised the storm cluster. The most severe storm always resulted in the most erosion during each cluster, no matter when it occurred within the chronology, although the erosion volume due to this storm was reduced when it was not the primary event. The greatest cumulative cluster erosion occurred with increasing storm severity; however, the vari-
\end{abstract}

ability in cumulative cluster impact over a beach/dune cross section due to storm chronology is minimal. Initial storm impact can act to enhance or reduce the system resilience to subsequent impact, but overall the cumulative impact is controlled by the magnitude and number of the storms. This model application provides inter-survey information about morphological response to repeated storm impact. This will inform local managers of the potential beach response and dune vulnerability to variable storm configurations.

\section{Introduction}

Natural coastal systems not only provide protection to coastal communities from flooding but also host both environmentally and economically important areas (Hanley et al., 2014). Foredunes are of importance to ecological habitats as well as of aesthetical value. Such sedimentary systems are at risk from naturally occurring coastal erosion and manmade intervention. For example, in the 1960s-1970s tourist urbanisation and road construction led to major alteration and destruction of extensive sand dune systems across Spain. The accelerated dune erosion was in response to interruptions of the littoral drift by harbour developments and sand mining for construction and agriculture, in addition to human trampling, refuse dumping, recreational pressure and cropping (Gómez-Pina et al., 2002). Across Europe, $25 \%$ of sand dunes were lost during the 20th century and up to $85 \%$ of the remainder may be threatened as a consequence of sea level 
rise and climate change (Hanley et al., 2014). In response to accelerated erosion artificial beach nourishment schemes have been widely implemented across Europe (Hanson et al., 2002).

Coastal storms are recognised as one of the most important driving agents responsible for the observed morphological changes within beach/dune systems (Tătu et al., 2014). Such systems can be viewed as adaptive through their beach/dune response to changes in energy from the forcing conditions (Hanley et al., 2014). It is therefore important to understand how the cross-shore beach/dune profile responds under temporal clusters in storm impacts to interpret the consequent changes in resilience and in turn the vulnerability of the dune system to repeat high energy shocks. To this end a case study of Formby Point (in the northwest of England) is used to assess sequences in storm impact on one of the largest dune systems in the UK. At this location, approximately $13 \mathrm{~m}$ of dune retreat was observed over the 2013/2014 winter period by the National Trust, the responsible authority for the management of this site (NT, 2014). Such information is therefore of importance to enable researched-informed shoreline management planning (Esteves et al., 2009).

The aim of this research is to investigate the cumulative change in beach/dune volume in response to the variation in the storm sequences to reduce the uncertainty in storm cluster impact. The impact of storm clusters has been investigated on a range of beaches by Ferreira (2005), Callaghan et al. (2008), Vousdoukas et al. (2012a) and Coco et al. (2013). Splinter et al. (2014) concluded that the cumulative cluster impact is insensitive to the sequence of events. This case study confirms these findings at this location but also assesses the change in dune impact from a single extreme event in response to a cluster of events evolving the ridge-runnel system on the lower beach face. This case study allows assessment of not only how a ridge-runnel system reduces dune erosion but also how this feature responses to a sequence of events of variable wave power. Analysis of a crosssectional transect enables detailed analysis of how sediment is redistributed across the beach/dune profile in response to storms of varying strength. It is suggested that sediment lost from the dune system enhances bar growth on the beach face, forcing waves to break further offshore and preventing further degradation of the dune system (Hanley et al., 2014). Understanding the likely response of the beach/dune profile to a sequence of storms is crucial for the development of appropriate and sustainable strategies to manage coastal flood and erosion risks.

\section{Study area: Formby point}

Formby Point is situated on the Sefton coast in Liverpool Bay and is one of the largest coastal dune systems in the UK (Fig. 1). Covering an area of 2100 ha, it extends $16 \mathrm{~km}$ alongshore and $4 \mathrm{~km}$ inland with dune heights reaching ap- proximately $30 \mathrm{~m}$ (Esteves et al., 2012). It supports a diverse range of habitats, including protected species such as the red squirrel and natterjack toad within the dune system (Edmondson, 2010). While vegetation (e.g. marram grass) is present the dune frontage at the profile of interest is relatively free from the influence of plant root stabilisation. Such biotic factors can play an important role on the dune stability increasing slope steepness (Armaroli et al., 2013). In this region the nearshore is characterised by a series of symmetrical sand ridges which are separated from the dune complex by a planer slope and are between 0.5 and $1.0 \mathrm{~m}$ high with a wavelength between 150 and $500 \mathrm{~m}$. These features are formed due to the large tidal range and wave dominance in shoreline evolution. Typically these features build up during calm periods and flatten during storms (Plater and Grenville, 2008).

The largest waves within Liverpool Bay reach $5 \mathrm{~m}$ and the coastal surges exceed $2 \mathrm{~m}$ (Brown et al., 2010). The mean spring tidal range is approximately $8.2 \mathrm{~m}$ at Liverpool (located at the southern extent of the Sefton coast; Esteves et al., 2012) and, when coinciding with veering winds from SW to $\mathrm{W}$, gives rise to the most extreme combined wave and water level conditions in Liverpool Bay (Brown et al., 2010). The wind climate within this region and the convex coastline geometry cause waves to focus on Formby Point, located at the coastal apex, while the net onshore tidal transport of sediment diverges into a net north and south littoral drift at this point (Pye and Neal, 1994). Formby Point therefore experiences a negative sediment supply, making it susceptible to storm-driven erosion (Pye and Blott, 2008). Dune retreat of up to $20 \mathrm{~m}$ has been observed along the Sefton coast and at Formby Point. It is suggested that significant winter erosion is caused when water levels exceed $4.87 \mathrm{~m} \mathrm{OD}(9.8 \mathrm{~m} \mathrm{CD}$ ) (Esteves et al., 2012).

Within this region, extensive coastal observations (Howarth et al., 2006) and shoreline monitoring by Sefton Metropolitan Borough Council (SMBC) has historically been carried out. At present, shoreline monitoring by SMBC of the coastal waves, circulation, beach profiles and shoreline position continues alongside an offshore wave rider buoy (WAV in Fig. 1), which forms part of the UK WaveNet system (maintained by Centre for Environment, Aquaculture and Fisheries Science - Cefas), that has been operational since 2005 in Liverpool Bay. A long-term tide gauge has also been maintained as part of the UK tide gauge network at Gladstone Dock, Liverpool (TG in Fig. 1). Using records of waves and water levels the recent storm cluster of December 2013-February 2014 has been found to consist of some of the most extreme conditions this coastline has experienced (Wadey et al., 2015). We therefore use this cluster of events to investigate how the chronology of wave events, with different wave power, causes variability in the system resilience to extreme events and the cumulative erosive impact on Formby Point. 


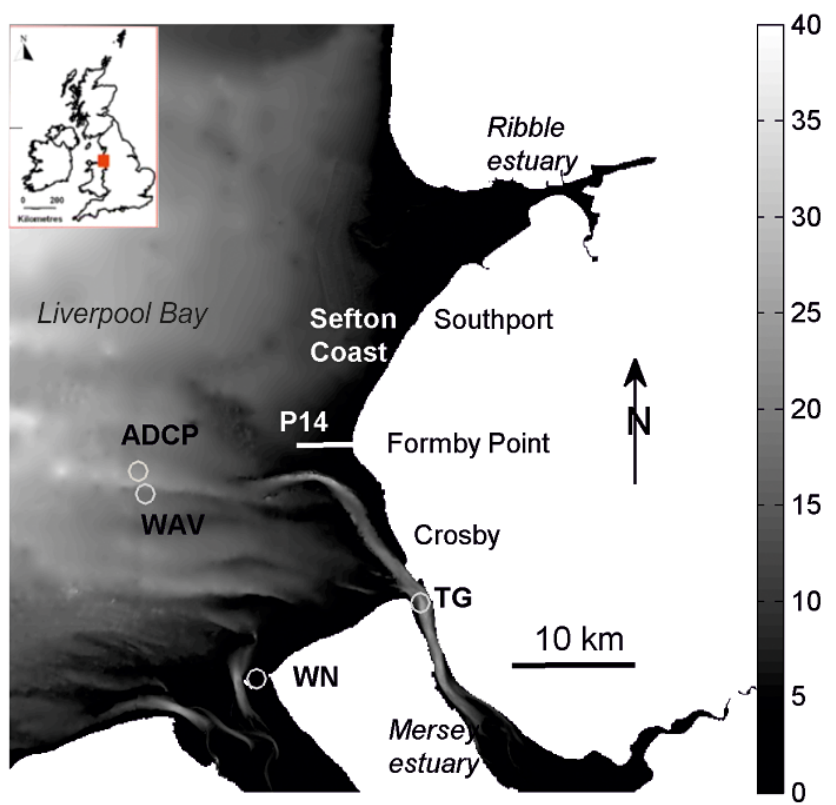

Figure 1. Liverpool Bay with the locations of the studied Formby Point transect P14, on the Sefton coast, and points of used observations; WAV (offshore wave characteristics), TG (Liverpool Gladstone Dock, nearshore tide) and WN (Hilbre wind station).

\section{Storm chronology}

The winter season 2013/2014 saw three events when the water elevation was able to allow wave impact and soaking of the dune toe, while there were seven extreme wave events impacting the shoreface. Beach surveys nearly 1 year later $(8$ October 2014) have shown that the dunes at the studied cross section have not fully recovered over an annual cycle. The frontage is still setback by approximately $5 \mathrm{~m}$ from the prestorm state (surveyed 10 September 2013). The ridge-runnel system has recovered, but sits slightly higher up the beach face, although this position could be related to the tidal conditions around the time of the surveys. This study uses three storm events (D1, D2 and J2) from the storm cluster that occurred from December 2013 to January 2014 to assess the impact of variable storm sequences on the ridge-runnel feature within the beach profile that influences the resilience of the beach/dune system at Formby Point. Such information will then be used to inform the wider community of the possible erosive threats of storm sequences to natural dune defence systems. The selected storms represent the first two that occurred in December and the second event that occurred in January. The extreme storm (D1, Fig. 2) is chosen due to the combination of large waves combined with a total water level that allows impact on the dune system, i.e. it exceeds the mean high water spring tide level $(4.47 \mathrm{~m}$ OD at Liverpool tide gauge) which the dune toe is typically located just above. This storm is the most extreme during the winter 2013/2014 period and causes approximately $4 \mathrm{~m}$ of dune retreat for the considered profile. The other two (D2 and J2) events are chosen to represent storms of different offshore wave severity but with a clear linear relation between the event severity. These events do not reach the dune toe, which typically has a mean winter position of $5.07 \mathrm{~m}$ OD (Esteves et al., 2012), but they do inundate the ridge-runnel feature. Selecting large wave events that can be related in terms of power is important to assess the morphological response of the ridge-runnel system. Unlike the dune response, the flattening of this feature is dependent on storm activity rather than the total water level. This allows the wave impact of different events on the ridge-runnel system to be assessed to identify whether the consequent morphological dune evolution in $\mathrm{D} 1$ is controlled by the timing of relative events. The relation between the wave power of all three events allows assessment of whether the ridge-runnel response is proportional to wave power of the number of repeated impacts. The first storm (D1 on 5 December) is the most powerful $\left(266 \mathrm{~m}^{2} \mathrm{~h}^{-1}\right)$. The second storm (D2 on 24 December) is approximately half the power (at $\left.110 \mathrm{~m}^{2} \mathrm{~h}^{-1}\right)$ of the first and the third storm (J2 on the 23 January) is approximately half the power (at $52 \mathrm{~m}^{2} \mathrm{~h}^{-1}$ ) of the second (and a quarter of the power of the first). We also calculate the offshore wave power for the full duration of the event when the total water elevation exceeds $1 \mathrm{~m}$ ODN (Ordnance Datum Newlyn), the approximate beach level at the start of the first ridge on the upper-beach face (see later Fig. 4) and $2 \mathrm{~m}$ ODN, the approximate elevation of the second ridge feature. The wave power was found to still have a similar ratio, decreasing by approximately a factor of 2 between each event.

Time variation of the wave height and water level within these events are shown in Fig. 2 together with the storm threshold wave height used to calculate the offshore storm wave power. In the first event (D1), which persisted about 1 day, the peak storm wave height $(4.6 \mathrm{~m})$ coincides with high water $(6.2 \mathrm{~m}$ ODN) during spring tide and strong westerly wind (note: wind characteristics are not shown here but are presented by Wadey et al., 2015). The second storm (D2) spanned about $19 \mathrm{~h}$ and occurred during the intermediate period between spring and neap tide. There were two peaks when this storm exceeded the wave threshold, with the wave heights reaching $2.8 \mathrm{~m}$ during the second peak. In this storm, the wind speed was higher at high water than at low water. The high water elevations reached 4.2 and $3.9 \mathrm{~m}$ ODN. The third storm (J2) lasted 8 hours and the peak storm wave height was $2.9 \mathrm{~m}$. A large part of the $\mathrm{J} 2 \mathrm{storm}$ coincided with the high-water spring tide ( $3.5 \mathrm{~m} \mathrm{ODN})$. Wind speed during this storm varied from 11 to $16 \mathrm{~m} \mathrm{~s}^{-1}$ whereas wind direction was almost similar to that of the westerly wave direction.

Using the three storm events, six storm clusters of different wave chronologies were simulated (Table 1) to investigate their impacts on the cumulative beach/dune response of Formby Point. 


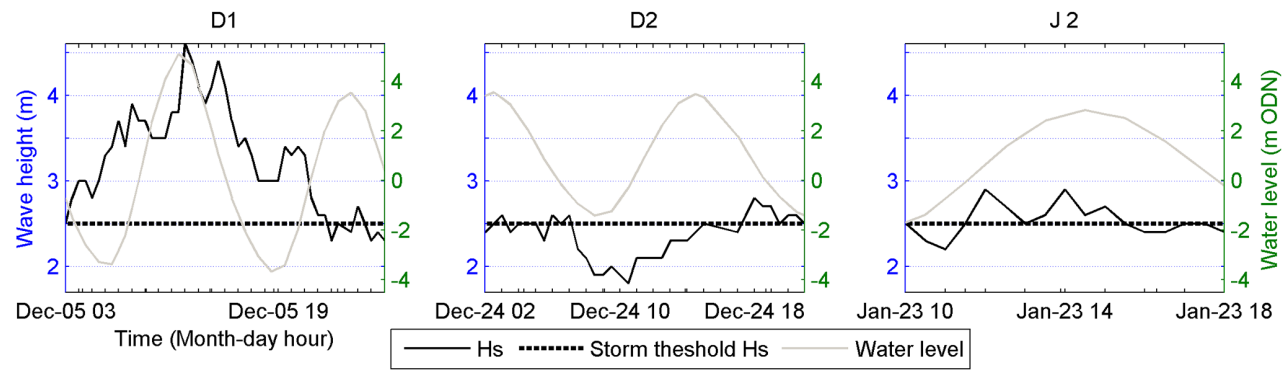

Figure 2. The three selected storm events D1, D2 (in December 2013) and J2 (in January 2014) and their wave height and water level variations together with the storm threshold wave height.

Table 1. Defined storm clusters using different storm wave chronologies of the three storm events (D1, D2 and J2).

\begin{tabular}{cl}
\hline Storm cluster & Storm chronology \\
\hline 1 & D1, D2, J2 \\
2 & D1, J2, D2 \\
3 & D2, D1, J2 \\
4 & D2, J2, D1 \\
5 & J2, D1, D2 \\
6 & J2, D2, D1 \\
\hline
\end{tabular}

\section{Model set-up}

The modelling system selected for this study is XBeach (Roelvink et al., 2009), which is one of the latest developed off-the-shelf models and is being continually improved by applications to different coastal environments worldwide (e.g. in Italy, Harley and Ciavola, 2013; Poland, Bugajny et al., 2013; Australia, Pender et al., 2014; the UK, Williams et al., 2011). This model has been proven to be capable of predicting storm impacts on morphodynamics of beach/dune systems in numerous case studies (Dissanayake et al., 2014; Souza et al., 2013; Harley and Ciavola, 2013; Splinter and Palmsten, 2012; Harley et al., 2011; Williams et al., 2011; McCall et al., 2010; Lindemer et al., 2010). The success of these previous applications motivated us to use XBeach in the present study, which aims to investigate the effects of wave chronology in a storm cluster on modifying the lower beach profile and therefore the impact of an extreme event on the dune system at Formby Point. It is noted that a 1-D approach was chosen to enable efficient computation time to perform multiple simulations of varied storm sequences. A 1-D application also removes the complication of alongshore transport in consequence to up-drift storm impact.

\subsection{Model domain}

We focus on a 1-D profile at the apex of the Sefton coast, Formby Point (transect P14 in Fig. 1), which extends from the upper dune crest across a routinely surveyed transect to

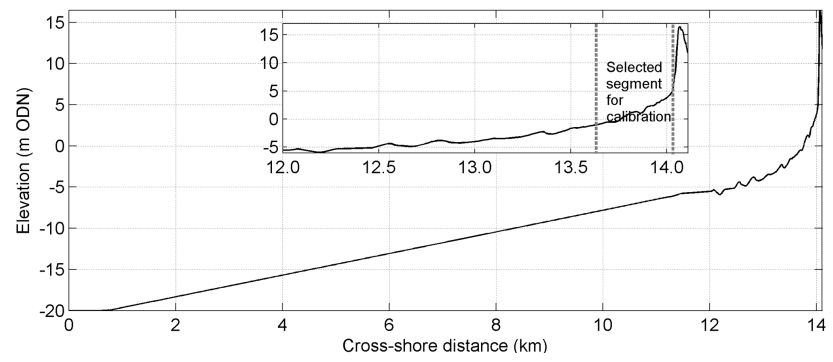

Figure 3. The pre-storm 1-D profile based on the observed data from survey location P14 (see Fig. 1). Calibration was performed over the transect length available from the post-storm survey.

the offshore wave rider buoy (Fig. 3). The chosen profile could therefore be forced, initialised and calibrated by observed conditions to reduce error. This beach cross section is centred on Formby Point and is susceptible to maximum wave impact, enabling assessment of storm-driven evolution at the most vulnerable section of the Sefton beach/dune system. This 1-D nearshore beach/dune profile (from the dune crest to $-2 \mathrm{~m}$ ODN depth) was defined by the surveyed pre-storm profile (on the 10 September 2013) provided by SMBC. The profile elevation from -2 to $-8 \mathrm{~m}$ ODN was estimated using the historical profile data from SMBC. A constant slope of $1: 500$ was then imposed from -8 to $-20 \mathrm{~m}$ ODN depth, based on the averaged offshore sea bed (used in local modelling studies by Brown et al., 2010). This was in order to extend the computational domain offshore to accurately impose the offshore boundary conditions from points of observation (Dissanayake et al., 2014). The offshore grid resolution was $50 \mathrm{~m}$ while the minimum grid size in the beach/dune region was about $1 \mathrm{~m}$ in order to accurately represent the bed topography. In this cross section, the dune toe is located at around $4.8 \mathrm{~m}$ ODN (Pye and Blott, 2008). Survey data collected on 9 December 2013 suggest that an erosion of $4 \mathrm{~m}$ occurred at the dune frontage of this transect during the D1 storm. A later survey, 8 October 2014, shows that the dune frontage has still not recovered nearly 1 year later. 


\subsection{Boundary forcings}

Wave, wind and tidal forcings during each event are separately applied to simulate the storms in the XBeach model. The extension of the model profile offshore to a $20 \mathrm{~m}$ depth enables us to set up the model such that it is forced with the observed waves at the offshore boundary (WAV in Fig. 1). Water levels at the offshore boundary are those recorded by a nearby tide gauge data at Gladstone Dock in Liverpool (TG in Fig. 1). This allows the tide, surge and any interaction to be imposed. Any local surge generation across the 1-D domain is assumed to be minimal and the tidal conditions are likely to be similar to those experienced at Formby Point. The location of the tide gauge in sheltered deep water within the Mersey estuary also means wave set-up in the observed water level is likely to be minimal, allowing XBeach to simulate this at the more open location. Wind speed and direction during each storm were extracted using the observed data at WN (see Fig. 1). The combination of these wave, wind and tidal characteristics provides the full model forcing for the offshore boundary of the investigated transect (P14).

\subsection{Model simulations}

Initial model simulations were undertaken to calibrate the model settings comparing the measured post-storm profile on 9 December 2013 and that of the model prediction during the D1 storm event. The calibrated model was then separately used to obtain the cumulative morphological change during the storm clusters defined in Table 1. The transect assessed (see Fig. 4, cross-shore distance 75-400 m) corresponds to the post-storm survey data that assessed the beach elevation to the newly eroded dune frontage. In the second series of simulations, the post-storm model predicted profile of the previous storm was adopted as the initial bed topography in the subsequent simulation to enable the cumulative response of beach/dune evolution within a storm cluster to be modelled.

\section{Model results and discussion}

\subsection{Model calibration}

The morphodynamic prediction of XBeach is sensitive to a number of model parameters (Pender and Karunarathna, 2013; McCall et al., 2010; Lindemer et al., 2010). The sensitivity to parameter settings is known to increase with stepper beach slopes (Vousdoukas et al., 2012b). Since this system is dissipative with a gentle slope, many of the default settings are appropriate. Only two parameters, found to cause the highest contribution to the modelled morphological changes of beach/dune systems, are used in this calibration: (1) the factor for time-averaged flows due to wave skewness ( $f a c S k$ ) and (2) the factor for time-averaged flows due to wave asymmetry $(f a c A s)$. The sediment transport rate in XBeach is es- timated using a representative velocity, which is a function of flow velocity and advection velocity from wave skewness and wave asymmetry (Roelvink et al., 2009). By applying different values for the calibration factors, of skewness $(f a c S k)$ and asymmetry $(f a c A s)$, the magnitude and direction of net sediment transport, and in turn the morphodynamic predictions, are changed. These coefficients generally vary from 0 to 0.8 according to the boundary forcings and topographic conditions of the study area (McCall et al., 2010).

A series of simulations were undertaken by changing the values of these two parameters systematically around the default settings. The optimised values for facSk and facAs were selected by comparing the predicted post-storm profile with that of the measured profile (Fig. 4) using two statistical parameters; the root-mean-square error (RMSE) and Brier skill score (BSS, see Van Rijn et al., 2003). The lowest RMSE (0.11) and the highest BSS (0.63) values were found using 0 for both facSk and facAs. The observed pre- and poststorm profiles indicate that the ridge-runnel formations are flattened during the storm event (D1). The measured poststorm profile shape (which covers the beach face to the above the dune toe at approximately $5.8 \mathrm{~m} \mathrm{ODN}$ ) is broadly reproduced by the model (see Fig. 4). This section represents the upper-beach and lower-dune interface, we see that the modelled profile is not flattened to quite the same extent as that observed and the dune erosion is not quite as observed. However, the model is simulating the event in isolation so does not account for dune soaking by the previous spring tides prior to the storm. For the chosen events only during D1 (Fig. 2) do water levels enable wave action to impact the dune face (see maximum water elevations in Fig. 2, D1 $=6.2 \mathrm{~m}$ ODN, $\mathrm{D} 2=4.2 \mathrm{~m}$ ODN, J2 $=3.5 \mathrm{~m}$ ODN). Following an extreme event continued erosion will be limited until the system recovers to those events that consist of even higher water elevations to allow the dune frontage to be reached while in a retreated position. This study therefore focuses on the upperbeach and lower-dune section from 0 to $+6 \mathrm{~m}$ ODN, consisting of the ridge-runnel system, where maximum evolution occurs. This is to identify how a sequence of storms modifies the beach profile, which in turn modifies the wave dissipation prior to dune impact during the most extreme events. This enables assessment of how weaker storms prior to an extreme event could modify the systems resilience and how weaker storms following an extreme event could still cause further impact.

These calibrated coefficients were used in the subsequent model runs to investigate the cumulative response of the beach/dune system to the variable wave chronology within the storm clusters.

\subsection{Profile evolution from mean sea level (MSL) contour to $+6 \mathrm{~m}$ ODN}

Here we compared the shape of profile evolution over the upper-beach and lower-dune system from 75 to $400 \mathrm{~m}$ cross- 


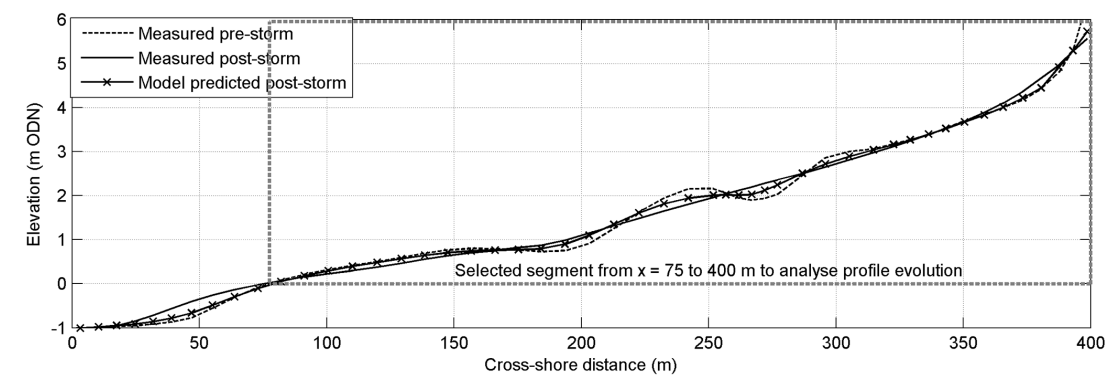

Figure 4. Comparison of measured and modelled profile evolution across transect P14 (13.65-14.00 km in Fig. 3) using the optimised calibration factors (facSk and facAs).

shore distance in Fig. 4 (i.e. from $0 \mathrm{~m}$ ODN, MSL, to $+6 \mathrm{~m}$ ODN) during each storm event within the defined storm clusters (Fig. 5). The initial profile is plotted alongside the profile after each event. We see there is a clear flattening of the ridge-runnel system and a retreat of the dune frontage. Slumping of the dune face causes a rise in elevation around the dune toe $(\sim 5 \mathrm{~m} \mathrm{ODN})$ and a setback at higher elevations (>5.8 $\mathrm{m} \mathrm{ODN}$ ) during the $\mathrm{D} 1$ event. In general for each cluster the first two storms flatten the ridge-runnel system and the third has minimal influence. The impact of the first storm depends on its severity; all storms act to flatten the ridgerunnel features. The second storm causes further flattening of this feature, but the actual change experienced is less than if the storm had impacted the undisturbed system. The third storm has minimal impact. At the dune toe the only storm that is able to cause slumping of the dune face and retreat is D1. No matter what the sequence of events is, the water levels in $\mathrm{D} 2$ and $\mathbf{J} 2$ prevent impact on the undisturbed dune profile or the retreated dune profile if they follow D1. The change in the ridge-runnel system and beach slope does not influence the ability of these storms to impact the dune toe. However, the morphological evolution due to these events does modify the impact of D1 on the dune system by up to approximately $0.02 \mathrm{~m}$ (see later Fig. 6a). Generally the erosion is increased when D1 follows J2 or D2 and J2 in any combination together, but it is reduced when it follows D2 alone. Under the initial storm the flattening of the ridge-runnel system also promotes accretion on the upper-beach face initialising the start of two small bars on the landward side of the last trough formation. These embryo bars are then eroded during the preceding storms. However, when D2 initialises the cluster the embryo bars are slightly larger and increase the system resilience reducing the impact of D1 on the dunes. The bar formation when $\mathrm{J} 2$ initialises the sequence is not large enough to reduce the impact of D1, but when $\mathrm{J} 2$ follows $\mathrm{D} 2$ the embryo bar is eroded, allowing D1 to have greater impact due to the repeated flattening of the ridge-runnel system.

These results show the importance of the wave chronology enabling weaker storms to modify the beach profile when they are in close succession to other storms, which influences the system's resilience to dune erosion. This is due to
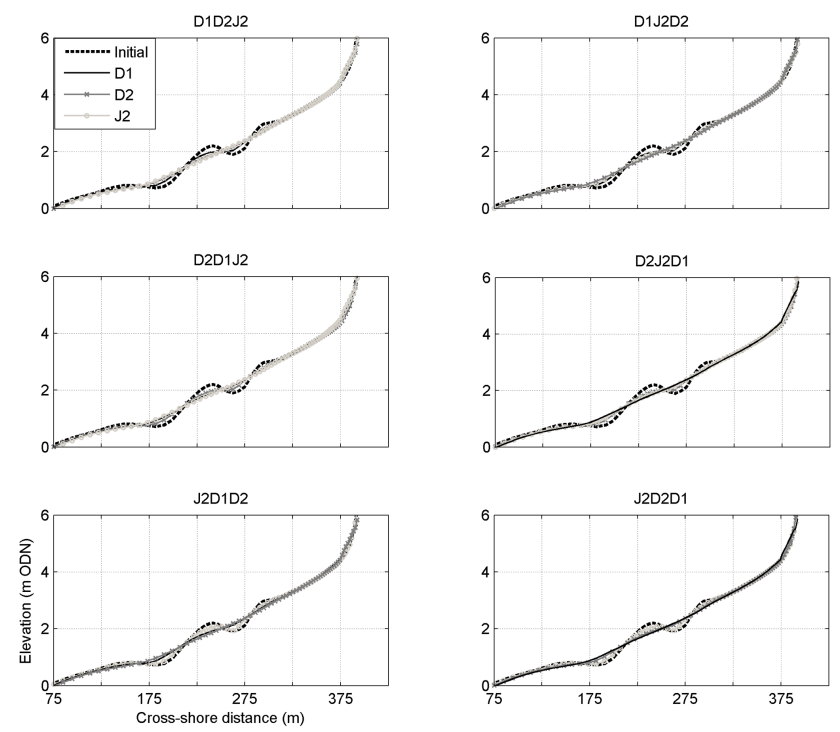

Figure 5. Profile evolution within the selected profile segment (from 75 to $400 \mathrm{~m}$ in Fig. 4) during each storm event within the six formulated storm clusters.

the flattening of the ridge-runnel system reducing the wave dissipation and also the redistribution of sediment from this feature to form new features further up the profile. The larger the proceeding event, the less impact weaker storms that follow it have on the ridge-runnel system; however, when if the weaker storms come first they modify the systems resilience of the upper beach and dunes to later extreme events.

\subsection{Bed level change during each storm event within the storm clusters}

Bed level changes during each storm event in the upperbeach/dune area are compared within each storm cluster (Fig. 6). The highest bed level changes within all storm events correspond to the region of the ridge-runnel system and the dune toe in the case of D1. The ridge crests at 230 and $290 \mathrm{~m}$ experienced erosion while accretion occurred in the troughs located at 190 and $260 \mathrm{~m}$ cross-shore distance. The dune frontage at $400 \mathrm{~m}$ experiences erosion under D1. 
The variable bed level change found for each storm event within the clusters indicates that event evolution depends on the wave chronology. Over the ridge-runnel system the magnitude of the bed level change corresponds to the events position in the cluster. When it occurs first the evolution is greatest and when it occurs last the evolution is smallest. These results suggest that after two storms in close succession, no matter what the storm power, this ridge-runnel system reaches a nearly stable (flattened) storm beach profile and noticeable evolution in response to further storms occurs only at the beach-dune interface if water levels allow. It is seen that when a storm initiates the cluster two small bars towards the landward side of the initial ridge-runnel system are initiated (at $\sim 306-335 \mathrm{~m}$ cross-shore distance, Fig. 6), but they become eroded on the second event.

At the dune, toe water elevation controls the storm impact as the waves either can or cannot reach the dunes. The variable response of $\mathrm{D} 1$, the only storm that can reach the dune system, is in relation to reduction of the dissipation by the ridge-runnel system and also the increase in bed level landward of the initial ridge-runnel system as new bars try to form further landward under the elevated water levels. For D1, the erosion of the dune frontage is quite consistent, demonstrating greater sensitivity to the water elevation than the dissipative nature of the ridge-runnel system on the wave conditions. The erosion is slightly increased when the ridgerunnel system is flattened and decreased when a bar starts to form under D2 at higher elevations on the beach (at 306$335 \mathrm{~m}$ ) when D2 precedes D1. Both D2 and J2 are unable to cause erosion of the dune system no matter what the sequence of events are that modify the beach/dune profile. J2 weakens the system resilience through flattening of the ridge and runnels. D2 increases the resilience due to the formation of slightly larger embryo bars on the upper-beach face than during $\mathrm{J} 2$; however, this resilience is lost if $\mathrm{J} 2$ follows D2 as the upper embryo bars are eroded. Also if D2 follows J2 the upper bars are not formed due to erosion of the initial system reducing sediment supply.

The time average of the absolute bed level change due to the three storm events run in sequence to form a cluster was separately analysed across the upper-beach region (Fig. 7). This represents the average effect of each storm sequence on the overall bed level change at select cross-shore locations representative of the ridge runnel features. The maximum event-average change of the bed level due to the clusters over the ridge-runnel system is about $(0.12 \mathrm{~m})$ half of that possible within a single storm event $(0.25 \mathrm{~m}$ in Fig. 6$)$. At the dune frontage the maximum time-averaged erosion is $(0.26 \mathrm{~m})$ is just less than a third of that possible within a single storm event $(0.77 \mathrm{~m}$ in Fig. 6$)$. This shows that while the ridgerunnel system evolution is influenced by approximately two storms the dune toe evolution is dominated by the single extreme event (D1).

Peak values in the averaged evolution (Fig. 7) correspond to the crests and troughs of the ridge-runnel formations of

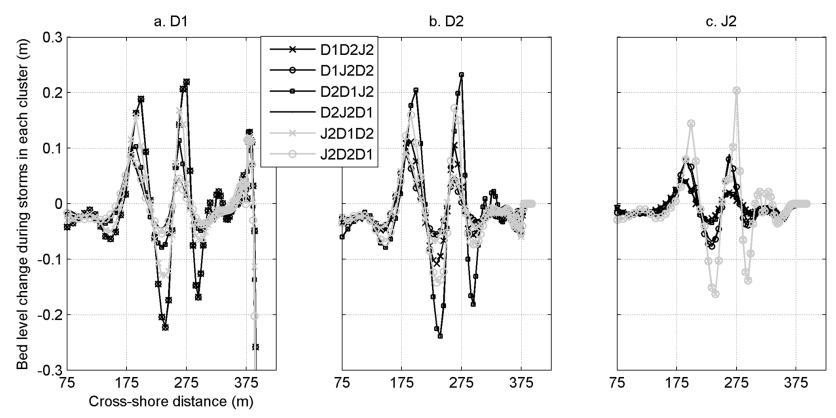

Figure 6. Bed level change from 75 to $400 \mathrm{~m}$ cross-shore distance during each storm event within each storm cluster. A positive change indicates accretion and negative is erosion. The erosion in (a) at the dune frontage reaches $-0.71,-0.71,-0.70,-0.73$, -0.77 and $-0.72 \mathrm{~m}$ in the order of the legend; not shown to enable a consistent and clear $y$ axis scale.

the initial profile (see Fig. 5), which experienced relatively large bed level change due to feature flattening compared with other locations across the profile. The first peak represents $(0.06 \mathrm{~m})$ erosion occurring on the bar located at $140 \mathrm{~m}$ cross-shore distance. The influence of all storm clusters is fairly similar at this location. The second peak at $190 \mathrm{~m}$ corresponds to the trough at $190 \mathrm{~m}$ cross-shore distance and its averaged bed change $(0.12 \mathrm{~m})$ is greater than that of the first peak, indicating strong deposition of slumped sediment from the bars at higher levels. The largest change at this location is found in cluster 4 while the lowest is given by the cluster 6 . In both clusters, the most severe storm (D1) occurred at the end. The third peak at $230 \mathrm{~m}$ cross-shore distance shows the greatest erosional impact across the experienced at the bar (at $230 \mathrm{~m}$ ) due to sediment at the crest being redistributed into the troughs either side. In this location, the largest average bed change is found under cluster 4 as well; whereas the smallest change resulted under the cluster 1 (i.e. D1 occurred initially). This is because D1 has the highest power, so once it has impacted this feature the latter storms that have less duration at this point in the profile due to lower water elevations and less power have less impact on the wider and lower feature. Deposition occurred in the trough located at $260 \mathrm{~m}$ cross-shore distance and is shown by the fourth peak. Cluster 2 produced the largest averaged bed change indicating the greatest deposition in this trough, while the lowest at this location was found in cluster 6 . In these two clusters, the D1 event occurred at the beginning and the end of the sequence. The last peak at $290 \mathrm{~m}$ indicates erosion on the bar located at the landward end. All storm clusters resulted in similar averaged bed change at the fifth peak, implying a similar impact of storm clusters on the bed at this bar's location. This suggests the infill was dominated by one event (D1) with the most impact at the higher elevations, potentially accessing sediment from further up the beach system.

The averaged bed change from $300 \mathrm{~m}$ landwards to the dune area is dominated by the erosion of the dune frontage 


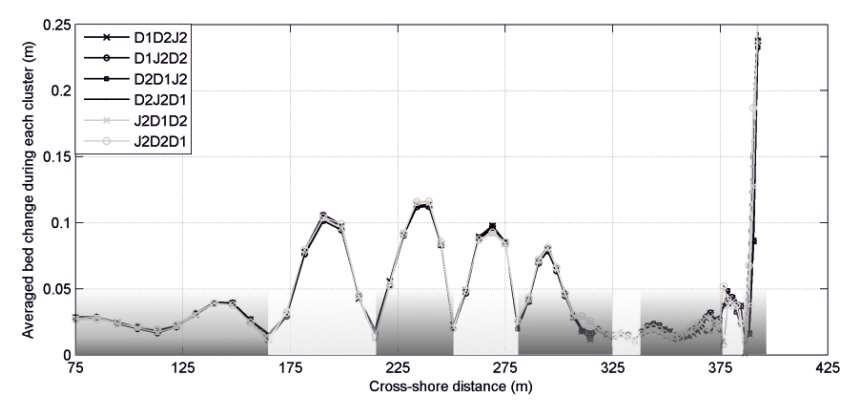

Figure 7. The time-averaged absolute bed level change from the 75 to $400 \mathrm{~m}$ cross-shore distance profile segment within each storm cluster. Dark grey indicates erosion areas while light grey indicates accretion. The grey area just landward of $325 \mathrm{~m}$ can accrete during the first event during the formation of the embryo bars. The fifth cluster just exceeds the $y$ axis scale causing an average change of $0.256 \mathrm{~m}$ at the dune toe.

which causes slumping at lower levels of the dune face seen as accretion (to $\sim 375 \mathrm{~m}$ ). Interestingly, at $\sim 300 \mathrm{~m}$ the clusters starting with $\mathrm{J} 2$ experience less erosion because the ridge-runnel system is still present and dissipating energy. The average impact on the dune frontage is typically higher for clusters 4, 5 and 6, suggesting the initial weak storm (J2) or initial combination of weaker storms (D2 and J2) reduces the system resilience due to the flattening of the ridge-runnel system prior to the impact of D1. There is no variability in the time-averaged impact on the dune toe between cluster 1 and 2, a consequence of the impact of D1 not causing a morphological change that enabled the later storms to reach the dune toe, which might have been achieved if the upper-beach elevation had dropped.

These results indicated that the average effect of the storm chronology within a cluster on the bed level change slightly varies with location along the profile. Also, no clear criterion is found such that the timing of the most severe storm, either at the start, middle or end, within a cluster influences the peaks in average erosion or deposition over the ridge runnel system. However, the time-averaged impact at the dune toe is greater when D1 follows $\mathbf{J} 2$. This is due to the modified impact of D1 rather than a combined impact of events.

\subsection{Volume change during each storm event and cluster event}

Volume change per unit cross-shore length was estimated during each storm event by multiplying the change in bed elevation and the cross-shore distance of grid cells along the selected profile segment from 75 to $400 \mathrm{~m}$ cross-shore length (black bar in Fig. 8). The volume change in response to the cluster of events was then found as the summation of the three storms (white bar in Fig. 8). A negative value indicates erosion and thus all storm events resulted in erosion over the upper-beach face. The event with the highest storm power $\left(266 \mathrm{~m}^{2} \mathrm{~h}^{-1}, \mathrm{D} 1\right)$ produced the highest erosion volume in each cluster, while the lowest volume is given by the weakest event $\left(52 \mathrm{~m}^{2} \mathrm{~h}^{-1}, \mathrm{~J} 2\right)$. The volume change during a storm event within a cluster tends to vary according to the offshore wave power, though it is not proportional to the wave power. The volume change induced by D2 $\left(110 \mathrm{~m}^{2} \mathrm{~h}^{-1}\right)$ is similar to that of D1 and the wave chronology seems to play an important role on the difference between these events. Comparing the volume change between D1, D2 and J2 when each event occurs as the initial storm clearly shows that even when the storms impact the same initial cross-shore profile the variability in the cross-shore volume change is not directly proportional the variability in offshore wave power. This will be a consequence of the coastal water elevations during the wave events, modifying the positions where the waves impact the shoreface. Also, smaller waves below the storm threshold during the event will redistribute sediment when the water elevations enable them to act on the beach. The timing of the wave events and associated surge relative to the tides is therefore important. We found the wave power ratio remains similar when looking at different water level thresholds over the ridge-runnel system; this suggests duration of activity above a water level threshold rather than wave magnitude may be a more important factor.

When looking at each storm event in turn, the greatest erosion volume associated with an event occurs when that storm is the initial event within a storm cluster. However, D1 has the same impact when it follows $\mathrm{J} 2$, if $\mathrm{J} 2$ leads the sequence, as it does in isolation. This is due to $\mathrm{J} 2$ having the least influence on the ridge-runnel system and no impact on the dunes. The variation in volume change associated with each event varies very little when the event is positioned differently in the storm sequence; however, it is slightly reduced when the event occurs later within the wave chronology. The amount of volume change is also found to depend on the storm wave severity of the preceding event. Increasing the proceeding event severity leads to a reduced erosion amount in the secondary event and decreasing the severity increases the erosion within the secondary event (e.g. compared D1 in the clusters 3 and 5) and thus shows the impact of storm wave sequence on the event-driven bed evolution. This result is due to the features of the bed profile being flattened by a variable amount, which then determines the continued evolution until the profile is flat. The cumulative volume changes, due to the three storm events within the clusters, indicate some variations due to wave chronology, though they are not significantly large. The largest cumulative volume change $\left(-11.14 \mathrm{~m}^{3} \mathrm{~m}^{-1}\right)$ is found in cluster 6 , which has the storm wave sequence of $\mathrm{J} 2, \mathrm{D} 2$ and D1. The second largest volume change $\left(-11.13 \mathrm{~m}^{3} \mathrm{~m}^{-1}\right)$ is caused by cluster 3 (D2, D1 and $\mathrm{J} 2$ ). The lowest erosion $\left(-11.01 \mathrm{~m}^{3} \mathrm{~m}^{-1}\right)$ resulted in the cluster 4 (D2, J2 and D1). It is seen that the wave chronology has little influence on the cumulative storm impact, that only the largest storms reach the dunes and that after two storms the ridge-runnel system is practically flattened. The fact that the largest cumulative evolution occurs with increasing wave 


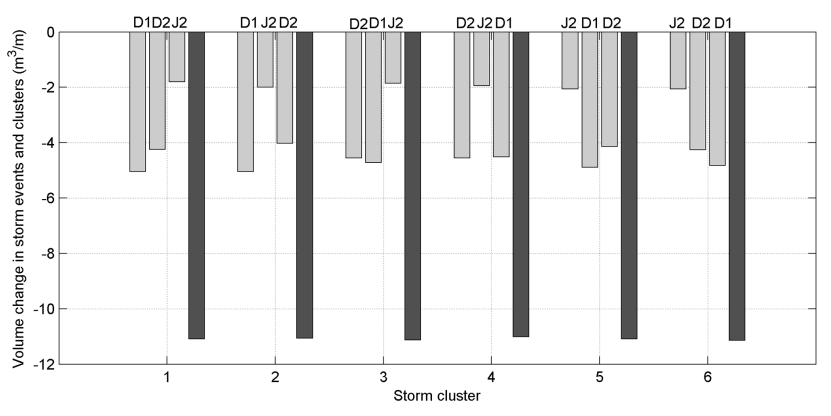

Figure 8. Comparison of the volume change from MSL to $+6 \mathrm{~m}$ ODN during each storm event and cluster. Grey bar at D1, D2 and $\mathrm{J} 2$ indicates volume change within the respective storm and black bar shows volume change within a cluster.

power is most likely due to the fact each successive storm can increase the erosive impact of the previous events and the system resilience is reduced after each event. The fact that cluster 3 has a large impact shows the evolution is dominated by the events D1 and D2. When the smallest event follows these events, it has least impact because the ridgerunnel system is flat and the storm cannot reach the dunes. The minimal cumulative evolution occurs when the moderate size storm impacts first, reducing the dissipative nature of the ridge-runnel system. The weaker storm, J2, then further flattens the ridge-runnel system and the main impact of D1 is limited to the dune system.

\section{Conclusions}

Impacts of storm chronology in a storm cluster on beach/dune erosion were investigated using a numerical model applied to Formby Point at the apex of the Sefton coast in the Liverpool Bay, UK. Three storm events that impact the ridge-runnel system with storm power values 266,110 and $52 \mathrm{~m}^{2} \mathrm{~h}^{-1}$ from the 2013/2014 winter storms were selected and formulated into six storm clusters using different wave chronologies. The most extreme of these events was able to impact the dune system due to the water level. The modelling approach used the XBeach coastal area model in a 1-D mode to simulate cross-shore profile evolution to assess how changes in the ridge-runnel system modify the dune impact of the extreme event. Offshore boundary forcings (i.e. water elevations and waves) were imposed using the observed data during the storms. The model was first calibrated against the available post-storm profiles. In each cluster, the predicted post-storm profile of the previous event was used as the initial pre-storm bed elevation for the subsequent event. The resulting evolution within the six clusters was analysed considering the upper-beach and lower-dune interface (from 0 to $+6 \mathrm{~m}$ ODN). Our analysis enhances the understanding of the importance of storm chronology within a storm cluster on beach/dune erosion at Formby Point and suggested the following conclusions.

- The most severe storm was used to calibrate the model. Comparison of the predicted post-storm profile with that of the measured profile resulted in an RMSE of $0.11 \mathrm{~m}$ and a correlation coefficient of 0.63 indicating a high storm model performance.

- Negligible variability in the cumulative impact of the storm clusters occurred in response to different storm wave chronologies. However, it was found that the event-scale ridge-runnel and dune face profile changed depending on the storm severity and the magnitude of the change was modified by previous events.

- Impacts of the storm clusters on bed change for this transect are mostly in relation to the flattening of the ridge-runnel system and slumping of the dune frontage.

- The largest event-driven bed level change occurred under the forcing of the most powerful storm event when it initialised the cluster. While the lowest bed level change occurred for the weakest event when it ended the cluster.

- The ridge-runnel system that exists on the upper-beach face at Formby Point lasts for about two storms in close succession, after which the upper beach becomes more susceptible to erosion. If the initial storm is weak the upper-beach face undergoes less evolution under later larger events, but the dune frontage is typically more susceptible to impact during later extreme events. Any morphological impact that occurs due to storms soon after is minimal as the beach forms have already been flattened, further erosion of the beach and cross-shore sediment exchange does not seem to occur. Continued response may result when longshore transport is considered.

- The highest erosion during each storm event was observed when that storm occurred as the initial event of a storm cluster. Within each cluster the most severe storm always resulted in the highest erosion and the weakest storm produced the lowest erosion no matter of its position within all clusters.

- In a storm cluster, the highest erosion on the beach/dune system was found when the storms increased in severity. The cumulative change in the ridge-runnel system is similar as it flattens so the change is likely to be related to a slight increase in erosion of the upper beach and the dune system during the most extreme event.

- Although the first storms acted to flatten the ridgerunnel system this had little influence on the volume change of the full profile in the last event, although it did influence the local change experienced close to the dune toe for the weaker storms when they occurred later. 
- Interestingly for this case study, a reduction in maximum water elevation during each storm event is consistent with a reduction in offshore storm wave power. This suggests the fetch-limited conditions of the Irish Sea and the orientation of this coast causes storms to generate similarity in the severity of the water and wave elevations that occur together.

- The storm events that were chosen to represent changing severity of impact on the lower beach features demonstrate how dune impact is more sensitive to events with high water levels than storm-driven changes in the beach profile. The ridge-runnel system therefore provides little increase in resilience for the dune system even when it is fully formed.

These results provide preliminary insights on the impacts of storm chronology within a storm cluster on the beach/dune erosion of Formby Point (Sefton coast). These findings will have important implications for the interpretation of the continued monitoring of the beach/dune erosion along the Sefton coast and will be useful to implement sustainable dune management strategies. Further model studies are now required to consider different profiles along the Sefton coast, storms with high water elevations and area simulation to get a comprehensive understand on the effects of the storm chronology. For other locations these results suggest that although wave chronology is important, influencing the event-scale morphological change, the cumulative impact is independent of the temporal sequencing.

Acknowledgements. The work presented in this paper was carried out under the project "FloodMEMORY (Multi-Event Modelling Of Risk and recoverY)" funded by the Engineering and Physical Sciences Research Council (EPSRC) under the grant number EP/K013513/1. The NOC COBS, BODC, NTSLF, the NOC marine data products team and CEFAS (WaveNet) are acknowledged for providing tidal and wave data. The Sefton Metropolitan Borough Council is acknowledged for providing access to relevant coastal monitoring used in this study. PD and HK also acknowledge the support of the Ensemble Estimation of Flood Risk in a Changing Climate project funded by the British Council through their Global Innovation Initiative.

Edited by: P. Ciavola

\section{References}

Armaroli, C., Grottoli, E., Harley, M. D., and Ciavola, P.: Beach morphodynamics and types of foredune erosion generated by storms along the Emilia-Romagna coastline, Italy, Geomorphology, 199, 22-35, 2013.

Brown, J. M.: A case study of combined wave and water levels under storm conditions using WAM and SWAN in a shallow water application, Ocean Model., 35, 215-229, 2010.

Bugajny, N., Furmańczyk, K., Dudzińska-Nowak, J., and PaplińskaSwerpel, B.: Modelling morphological changes of beach and dune induced by storm on the Southern Baltic coast using XBeach (case study: Dziwnow Spit), edited by: Conley, D. C., Masselink, G., Russell, P. E., and O'Hare, T. J., Proceedings 12th International Coastal Symposium (Plymouth, England), J. Coast. Res., 65, 672-677, 2013.

Callaghan, D. P., Nielson, P., Short, A. D., and Ranasinghe, R.: Statistical simulation of wave climate and extreme beach erosion, Coast. Eng., 55, 375-390, 2008.

Coco, G., Senechal, N., Rejas, A., Brian, K. R., Capo, S., Parisot, J. P., Brown, J. A., and MacMahan, J. H. M.: Beach response to sequence of extreme storms, Geomorphology, 204, 493-501, 2013.

Dissanayake, P., Brown, J., and Karunarathna, H.: Modelling storminduced beach/dune evolution: Sefton coast, Liverpool Bay, UK, Marine Geol., 357, 225-242, 2014.

Edmondson, S. E.: Dune Slacks on the Sefton Coast, Sefton's Dynamic Coast, Proceeding of the conference on coastal and geomorphology, Biogeogr. Manage., 178-187, 2010.

Esteves, L. S., Williams, J. J., Nock, A., and Lymbery, G.: Quantifying shoreline changes along the Sefton Coast (UK) and the Implications for Research-Informed Coastal Management, J. Coast. Res., 56, 602-606, 2009.

Esteves, L. S., Brown, J. M., Williams, J. J., and Lymbery, G.: Quantifying thresholds for significant dune erosion along the Sefton Coast, Northwest, England, Geomorphology, 143-144, 52-61, 2012.

Ferreira, O.: Storm groups versus extreme single storms: predicted erosion and management consequences. J. Coast. Res., 42, 221227, 2005.

Gómez-Pina, G., Muñoz-Pérez, J. J., Ramírez, J. L., and Ley, C.: Sand dune management problems and techniques, Spain, J. Coast. Res., SI 36, 325-332, 2002.

Hanley, M. E., Hoggart, S. P. G., Simmonds, D. J., Bichot, A., Colangelo, M. A., Bozzeda, F., Heurtefeux, H., Ondiviela, B., Ostrowski, R., Recio, M., Trude, R., Zawadzka-Kahlau, E., and Thompson, R. C.: Shifting sands? Coastal protection by sand banks, beaches and dunes, Coast. Eng., 87, 136-146, 2014.

Hanson, H., Brampton, A., Capobianco, M., Dette, H. H., Hamm, L., Laustrup, C., Lechuga, A., and Spanhoff, R.: Beach nourishment projects, practices and objectives-a European overview, Coast. Eng., 47, 81-111, 2002.

Harley, M. D. and Ciavola, P.: Managing local coastal inundation risk using real-time forecasts and artificial dune placements, Coast. Eng., 77, 77-90, 2013.

Harley, M. D., Armaroli, C., and Ciavola, P.: Evaluation of XBeach predictions for a real-time warning system in Emilia-Romagna, Northern Italy, J. Coast. Res., 64, 1861-1865, 2011.

Howarth, M. J., Proctor, R., Knight, P. J., Smithson, M. J., and Mills, D. K.: The Liverpool Bay 674 Coastal Observatory: to- 
wards the goals, Proceedings of Oceans '06, MTS/IEEE, Boston, p. 6, doi:10.1109/OCEANS.2006.307095, 2006.

Lindemer, C., Plant, N., Puleo, J., Thompson, D., and Wamsley, T.: Numerical simulation of a low-lying barrier island's morphological response to Hurricane Katrina, Coast. Eng., 57, 985-995, 2010.

McCall, R., Van Thiel de Vries, J., Plant, N., Van Dongeren, A., Roelvink, J., Thompson, D., and Reniers, A.: Two-dimensional time dependent hurricane overwash and erosion modelling at Santa Rosa Island, Coast. Eng., 57, 668-683, 2010.

NT: How have the storms affected the coast? The National Trust - coast \& countryside, available at: http://www.nationaltrust. org.uk/article-1355824158683/ (last access: 10 February 2015), 2014.

Pender, D. and Karunarathna, H.: A statistical-process based approach for modelling beach profile variability, Coast. Eng., 81, 19-29, 2013.

Pender, D., Callaghan, D. P., and Karunarathna, H.: An evaluation of methods available for quantifying extreme beach erosion, J. Ocean Eng. Mar. Energy, 1, 31-43, doi:10.1007/s40722-0140003-1, 2014.

Plater, A. J. and Grenville, J.: Liverpool Bay: linking the eastern Irish Sea to the Sefton Coast, Sefton's Dynamic Coast, Proceeding of the conference on coastal and geomorphology, Biogeogr. Manage., 41-43, 2008.

Pye, K. and Blott, S. J.: Decadal-scale variation in dune erosion and accretion rates: an investigation of the significance of changing storm tide frequency and magnitude on the Sefton Coast, UK, Geomorphology, 102, 652-666, 2008.

Pye, K. and Neal, A.: Coastal dune erosion at Formby Point, north Merseyside, England: causes and mechanisms, Marine Geol., 119, 39-56, 1994.
Roelvink, D., Reniers, A., van Dongeren, A., Van Thiel de Vries, J., McCall, R., and Lescinski, J.: Modelling storm impacts on beaches, dunes and barrier islands, Coast. Eng., 56, 1133-1152, 2009.

Souza, A. J., Brown, J. M., Williams, J. J., and Lymbery, G.: Application of an operational storm coastal impact forecasting system, J. Operat. Oceanogr., 6, 23-26, 2013.

Splinter, K. D. and Palmsten, M. L.: Modelling dune response to an East Coast Low, Marine Geol., 329-331, 46-57, 2012.

Splinter, K. D., Carley, J. T., Golshani, A., and Tomlinson, R.: A relationship to describe the cumulative impact of storm clusters on beach erosion, Coast. Eng., 83, 49-55, 2014.

Tâtui, F., Vespremeanu-Stroe, A., and Preoteasa, L.: Alongshore variations in beach-dune system response to major storm events on the Danube Delta coast, J. Coast. Res., SI 70, 693-699, 2014.

Van Rijn, L. C., Walstra, D. J. R., Grasmeijer, B., Sutherland, J., Pan, S., and Sierra, J. P.: The predictability of cross-shore evolution of sandy beaches at the scale of storm and seasons using process-based profile models, Coast. Eng., 47, 295-327, 2003.

Vousdoukas, M. I., Almeida, L. P., and Ferreira, O.: Beach erosion and recovery during consecutive storms at a steep-sloping, mesotidal beach, Earth Surf. Proc. Landf. 37, 583-593, 2012a.

Vousdoukas, M. I., Ferreira, O. Almeida, L. P., and Pacheco, A.: Toward reliable storm-hazard forecasts: XBeach calibration and its potential application in an operational early-warning system, Ocean Dynam., 2, 1001-1015, 2012 b.

Wadey, M., Brown, J. M., and Haigh I.: Assessment and comparison of extreme sea levels and waves during the 2013/14 storm-tide season in two UK coastal regions, 3, 2665-2708, 2015.

Williams, J. J., Brown, J., Esteves, L. S., and Souza, A.: MICORE WP4 Modelling coastal erosion and flooding along the Sefton Coast NW UK, final report, available at: http://www.micore.eu, 2011. 